\title{
The role of lambs in louping-ill virus amplification
}

\author{
M. K. LAURENSON ${ }^{1,2 *}$, R. NORMAN ${ }^{3}, H$. W. REID ${ }^{4}$, I. POW ${ }^{4}, \mathrm{D}^{2} \mathrm{NEWBORN}^{2}$ and \\ P. J. HUDSON ${ }^{1}$ \\ ${ }^{1}$ Institute of Biological Sciences, University of Stirling, Stirling FK9 4LA \\ ${ }^{2}$ The Game Conservancy Upland Research Group, Crubenmore Lodge, Newtonmore, Inverness-shire PH20 1BE \\ ${ }^{3}$ Department of Mathematics and Computing, University of Stirling, Stirling FK9 4LA \\ ${ }^{4}$ The Moredun Research Institute Pentlands Science Park, Bush Loan, Penicuik, Midlothian EH26 OPZ
}

(Received 9 June 1999; revised 27 August 1999; accepted 29 August 1999)

\section{SU M M A R Y}

In some areas of Scotland, the prevalence of louping-ill virus has not decreased despite the vaccination of replacement ewes for over 30 years. The role of unvaccinated lambs in viral persistence was examined through a combination of an empirical study of infection rates of lambs and mathematical modelling. Serological sampling revealed that most lambs were protected by colostral immunity at turnout in May/June but were fully susceptible by the end of September. Between 8 and $83 \%$ of lambs were infected over the first season, with seroconversion rates greater in late rather than early summer. The proportion of lambs that could have amplified the louping-ill virus was low, however, because high initial titres of colostral antibody on farms with a high force of infection gave protection for several months. A simple mathematical model suggested that the relationship between the force of infection and the percentage of lambs that became viraemic was not linear and that the maximum percentage of viraemic lambs occurred at moderately high infection rates. Examination of the conditions required for louping-ill persistence suggested that the virus could theoretically persist in a sheep flock with over 370 lambs, if the grazing season was longer than 130 days. In practice, however, lamb viraemia is not a general explanation for louping-ill virus persistence as these conditions are not met in most management systems and because the widespread use of acaracides in most tick-affected hill farming systems reduces the number of ticks feeding successfully.

Key words: louping-ill virus, virus amplification, sheep, lambs, Ixodes ricinus.

\section{INTRODUCTION}

Louping-ill virus (LIV) is a tick-borne virus that causes encephalomyelitis in a number of species. In upland Britain, two vertebrate hosts, sheep and red grouse (Lagopus lagopus scoticus), exhibit a postinfection viraemia sufficient for feeding tick instars to acquire the virus (Beasley, Campbell \& Reid, 1978; Reid, 1978). The role of red grouse is considered relatively unimportant since up to $78 \%$ of grouse die from infection (Reid, 1975) and this mortality leads to a decline in red grouse productivity and density in highly endemic areas (Reid et al. 1978; Hudson, 1992). Louping-ill virus persistence has thus been considered to be largely dependent on sheep (Reid, 1978) and thus the removal of sheep (or their effective removal through vaccination against louping-ill) should reduce infection rates and lead to a fall in the prevalence of the virus.

Vaccination to reduce losses from louping-ill has been an integral component of sheep management in many affected areas of Great Britain since the vaccine first became available in the 1930s (Gordon, 1934). Generally, graziers use only a single vaccination of

* Corresponding author: CTVM, Royal (Dick) School of Veterinary Studies, Easter Bush, Roslin, Midlothian EH25 9RG. Tel: + 0131650 6404. Fax: + 01316506216. E-mail: karen.laurenson@ed.ac.uk yearling ewes, despite the recommended use of a double vaccination at least a month apart which prevents the decline of antibody titres in older ewes (Reid \& Pow, 1995). Lambs acquire protection against louping-ill virus infection by ingesting colostrum, but as antibody titres decline during the summer grazing season, lambs become susceptible. If lambs are bitten by a louping-ill virus-infected tick when they still have high levels of colostral antibody, lambs may be refractory to infection. When colostral antibody levels are lower, the lambs' immune system may be sensitized to the virus and lambs can acquire life-long immunity, but the severity of infection is limited by the presence of colostral antibody. If infected when colostral antibody has completely declined, lambs will be fully susceptible. With initial antibody levels in lambs corresponding to those in their dams, lambs from older ewes that have been vaccinated only once will become susceptible to LIV more rapidly.

Despite the vaccination of sheep for over 30 years, the prevalence of louping-ill virus infection in red grouse and sheep has not reduced in some areas, particularly certain regions in Scotland (Hudson et al. 1995). Several hypotheses could account for this observation. First, with adequate alternative hosts for the adult tick, grouse populations may be able to sustain the virus population (Hudson et al. 1995). Second, non-viraemic transmission between co- 
feeding ticks on non-viraemic hosts may allow virus persistence (Jones et al. 1987; Ogden, Nuttall \& Randolph, 1998). Third, if enough lambs are infected when maternally-acquired immunity has waned, they may amplify the virus and allow the virus to persist.

In this paper, we investigate the last of these hypotheses. For lambs to amplify louping-ill virus, some lambs from vaccinated mothers must be susceptible to infection during the summer and some must be infected. Thus we examine empirically (a) the titres of colostral-derived antibody in lambs and the percentage of lambs susceptible to infection during their first season on pasture, (b) the rate at which lambs seroconvert and thus have been infected with louping-ill virus and (c) the percentage of the lamb flock that may have become viraemic on infection. We then proceed to examine, through simple models, the relationship between the force of infection and the number of lambs that could be viraemic and consider the conditions under which lambs could allow louping-ill virus persistence.

\section{MATERIALS AND METHODS}

Lambs on 9 upland farms on 3 sporting estates were sampled in the autumn 1993 with 2 farms sampled on the first estate (Morayshire), 1 on the second (Perthshire) and 6 on the third (North Yorkshire Moors). Mountain hares (Lepus timidus) were present on Scottish farms but not on English farms. On the 2 Morayshire farms and 2 of the English farms, 1 -year-old ewes were vaccinated in March/April each year with $1 \mathrm{ml}$ of louping-ill vaccine (ScheringPlough Animal Health). At least 25 lambs were sampled at random when lambs were either taken off the hill in September/October or when ewes were gathered in November.

In 1995 a more intensive sampling regime was adopted on 4 farms, 2 in Morayshire, Scotland (S1 and S2) and 2 in North Yorkshire, England (E1 and E2). Selected lambs were either ear tagged or, on 1 estate in Scotland, individually recognized by the shepherd. The prevalence of louping-ill, as measured by seroprevalence in red grouse, was high on the Scottish estate ( $\sim 80 \%$ seropositive), and yearling ewes were inoculated with louping-ill vaccine to prevent losses. On the other estate in England, louping-ill was less prevalent ( $\sim 10 \%$ seropositive) but varied considerably in different areas. The yearlings on 1 farm (E2) were also vaccinated.

Ewes were mated after 28 November on all farms and lambs were born in late April and early May. For simplification, a lambing date of 1 May is assumed for all individuals. Lambs were blood sampled 3 times; when turned out or gathered in May/June (aged 4-6 weeks), when ewes were clipped in mid-July (aged 11-13 weeks) and again after being removed from the hill in September/October (aged
18-22 weeks). Ewe lambs from farm S1 in Morayshire (see Table 1) that had been retained overwinter were resampled at the end of March 1996. Lambs were all treated with acaracidal pour-on when turned out or gathered in late May (England) or June (Scotland). Lambs were then treated again at clipping time with either pyrethroid pour-on or dip. Lambs on farm E2 North Yorkshire had an additional pour-on treatment in August.

Haemagglutination-inhibiting antibody (HIA) to louping-ill virus in sera was determined using gander red blood cells as described by Clarke \& Casals (1958) except that the diluted serum was extracted with an equal volume of kaolin suspension. Reciprocal HIA titres are reported, with those $\geqslant 10$ being regarded as seropositive.

Lambs sampled at either 11-13 weeks or at 18-22 weeks were deemed to have seroconverted and thus to have been infected if their reciprocal HIA titre was at least 2 dilutions higher than that predicted by the exponential decay curve of the colostral antibody titre when previously sampled. The decay was estimated from $x(t)=\mathrm{e}^{-0 \cdot 05 t}$, calculated from a halflife of 14 days (Reid \& Boyce, 1976). Apart from the few known cases with particularly high colostral titres (Fig. 2), all other colostral antibodies would have decayed to undetectable levels by September/ October when lambs were 18-22 weeks old, and so seropositivity of lambs sampled at this time indicated that lambs had been exposed to the virus. As the Scottish lambs were sampled for the first time 2 and 3.5 weeks later than the English lambs, the reciprocal HIA titres were increased by 1 (2 weeks) or $2(3.5$ weeks) dilution for comparison (Fig. 2).

This measure of seroprevalence and infection rates fails to take into account infection of lambs that might have died from louping-ill. We assumed that $10 \%$ of infected lambs died and thus that the survivors represented $90 \%$ of infected lambs. Infection rates extrapolated from seroconversion rates (assuming that every lamb that seroconverted must have been infected by the virus) were adjusted accordingly.

\section{Calculation of whether lambs were viraemic when infected}

The number of days that each lamb was susceptible to infection was estimated from the measured levels of HIA at each sampling point and the above decay rate. Lambs were also considered to be refractory to infection for 34 days after HIA was last detectable (Reid \& Boyce, 1976) as lambs negative for HIA antibody 20 days before challenge did not become viraemic but those negative at 48 days did become viraemic. The number of days each lamb was susceptible was then summed and divided by the total number of days all lambs were potentially exposed to the virus. This figure was then multiplied 
by the percentage of lambs infected during the period, to give an estimate of the percentage of surviving lambs that could have become viraemic on infection.

The proportion of the flock infected each day was not, however, constant over the period due to variations in tick activity. To give a relative estimate of exposure during the period, an index of tick activity each week was used to assess how infection rates varied from week to week. In Morayshire, where we recorded a unimodal pattern of tick activity between April and October through assessing the tick burdens of mountain hares (unpublished data), the relative infection rate for each week was calculated by dividing the mean tick burden on hares that week by the sum of tick burdens and multiplying by the weekly infection rate for the whole period. In northeastern England, where there is generally a bimodal pattern of tick activity with a distinct spring and autumn rise (Milne, 1947; Gray, 1991), tick burdens on sheep were used to estimate the relative infection rate for each week as above. The estimate of the percentage of lambs that might have become viraemic on infection was then recalculated using these modified weekly infection rates. These estimates are reported in Table 2 as the minimum percentage of lambs that may have been viraemic following infection.

This estimate, however, does not take account of mortality due to louping-ill, which is difficult to quantify in the field. Tagged lambs may not have been resampled for several reasons; they may have died, they may not have been gathered or they may have lost their ear tag. Losses of between 7 and $35 \%$ between lambing and weaning were reported on these farms, but post-mortem material was obtained from only 1 lamb, which did prove positive for louping-ill virus. Farm E1 suffered the highest losses, with many lambs run over on a busy road across the moor. Moreover, in experimental conditions, louping-ill mortality rates are very variable and depend on a number of factors, such as concurrent infection with tick-borne fever, stress and weather (Reid et al. 1986). Given these difficulties 2 estimates of mortality due to louping-ill were used. First, $10 \%$ of infected lambs were assumed to die, as above, but a second upper estimate was also used that assumed that all missing lambs with reciprocal antibody titres of $\leqslant 20$ when last sampled (S1:1/27, S2:2/31, E1:5/34, E2:4/37), died of louping-ill (Table 2).

\section{Model A. Transmission of louping-ill virus infection in lambs}

We developed a model to examine the effect of variation in the force of infection on the percentage of lambs that became viraemic, according to the immune status of lambs (Fig. 1). The model considers lambs to be in 1 of 4 categories: susceptible $\left(L_{s}\right)$, infected (viraemic, $L_{v}$ ), those with maternally acquired immunity $\left(L_{I 1}\right)$ and those permanently immune after infection $\left(L_{I 2}\right)$. The lamb population and the force of infection $b$, the probability of being bitten by an infection tick per day, were assumed to be constant.

The model is described through a series of coupled differential equations :

$$
\begin{aligned}
d L_{I 1} / d t & =-b L_{I 1}-a L_{I 1} \\
d L_{s} / d t & =a L_{I 1}-b L_{s} \\
d L_{v} / d t & =b L_{s}-g L_{v} \\
d L_{I 2} / d t & =g L_{v}+b L_{I 1}
\end{aligned}
$$

The proportion of lambs with maternally acquired immunity at turnout, $p$, varied with the force of infection, with the remainder already being in the susceptible class. The rate at which lambs lost maternally acquired antibody and became susceptible, $a(t)$ was calculated using the method described by Woolhouse et al. (1996).

The distribution of $\log _{10}$ maternal antibody titres is described by a normal probability density function $N\left(A(t), \sigma^{2}\right)$ where $A(t)$ is the mean log antibody titre at time $t$ after birth and the variance, $\sigma^{2}$, is independent of $A$ and $t$. We assume an exponential decay in maternal antibody titre, and therefore we can express the mean log maternal antibody titre at time $t$ as $A(t)=A_{\text {int }}-\gamma t$ where $\gamma$ is a measure of the decay rate of antibody titre and $A_{i n t}$ is the initial

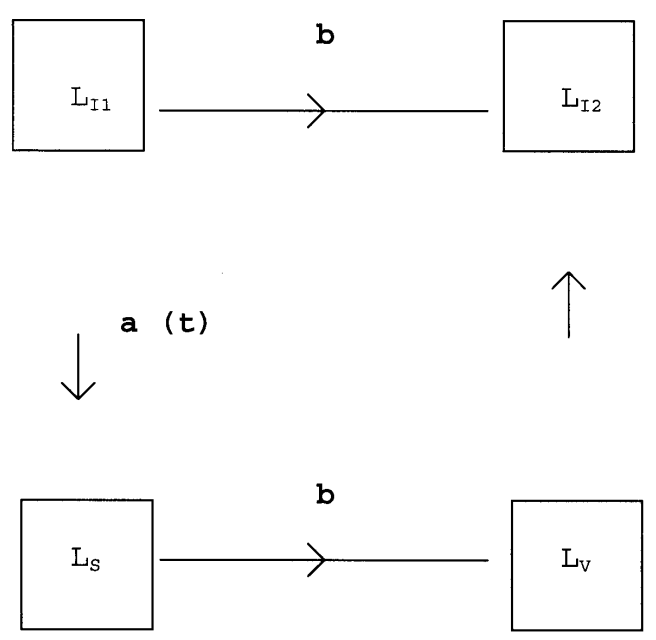

Fig. 1. Flow diagram of immune status of lambs to louping-ill virus. Lambs are born into class $L_{I 1}$ where they have a level of maternally-acquired immunity through the colostrum. As maternal immunity wanes with $t_{1 / 2}=14$ days, lambs become susceptible, entering the $L_{s}$ class at a rate of $a(t)$. Lambs are infected with louping-ill virus at a rate of $b$ (the force of infection); if infected whilst they still have a degree of maternal immunity, they go straight into the $L_{I 2}$ (permanently immune) class, but if infected whilst susceptible, they become viraemic $\left(L_{v}\right)$, before becoming permanently immune at rate $g$, after a viraemia of 2 days. 
$\log$ maternal antibody titre. We define a threshold log maternal antibody titre, $A_{\text {crit }}$, below which lambs are susceptible to louping-ill virus.

Following Woolhouse et al (1996), the expression for the proportion of lambs which have antibody titres above the threshold at time $t$ after birth, $p(t)$, is given by

$p(t)=\frac{1}{2} \operatorname{erfc}\left(\frac{\gamma t-A_{\text {int }}+A_{\text {crit }}}{\sigma \sqrt{ } 2}\right)$

where the term erfc is the complement of the error function (Papoulis, 1965).

Estimates of parameter values and boundaries for high, medium and low rates of infections were obtained from the data set and were, respectively, $0.0227,0.0119$ and 0.0011 for $b ; 1,0.9$ and 0.75 for $p$; $2 \cdot 406,2 \cdot 204$ and 1.75 for $A_{\text {int }}$ and $0 \cdot 3,0.4043$ and 1.13 for $\sigma^{2}$. In all cases $A_{\text {crit }}$ is taken to be $1, g=0.5$ and $\gamma=0.0215$ (based on a half-life of 14 days). $A_{i n t}$ varies between 2.4 (high) and 1.75 (low) with variances ranging from $0 \cdot 3$ (high) to $1 \cdot 13$ (low).

The total percentage of lambs in a flock that had been viraemic after infection by the end of the season was obtained by summing the percentage of lambs in the viraemic class each day (the area under the curves in Fig. 3) and then dividing by 2 (the number of days that lambs are viraemic).

\section{Model B. Conditions for louping-ill virus persistence}

We constructed a simulation model to assess whether louping-ill could persist in this system. In this model, each lamb is bitten $T$ times per season, with $T$ consisting of larvae $(A)$, nymphs $(B)$ and adults $(C)$, such that $A+B+C=T$. Adults and nymphs can be susceptible $\left(B_{s}\right.$ or $\left.C_{s}\right)$ or infected $\left(B_{i}\right.$ or $\left.C_{i}\right)$ with the louping-ill virus. Lamb population size is denoted by $L$, of which a proportion $p$ are immune at the beginning of the season. Immunity lasts for $d_{i}$ days and thus they are susceptible for $d-d_{i}$ days, where $d$ is the maximum length of the season. The number of lambs which become infected in a season $n$ is then denoted as $L_{n}$ and each infected lamb is viraemic for $v$ days. The mean number of days that lambs are susceptible in season $n$ is thus

$D_{n}=d-p d_{i}=\left[(1-p) L d+p L\left(d-d_{i}\right)\right] / L$.

The proportion immune, $p$, and $d_{i}$ both depend on the force of infection, $\beta$, in the previous season whilst $d$ is constant. The relationship between $p$ and $d_{i}$, estimated from data followed a logistic function, such that

$p=k_{p} \mathrm{e}^{r p \beta} /\left(1+\mathrm{e}^{r p \beta}\right)$,

where $k_{p}=1, r_{p}=998 \cdot 738$, since $p$ cannot exceed 1 , so when $\beta=0.001, p=0.75$ and

$d_{i}=k_{d} \mathrm{e}^{r d \beta} /\left(1+\mathrm{e}^{r d \beta}\right)$,

where $k_{d}=121, r_{d}=1134$, since $d_{i}$ cannot exceed 121 and when $\beta=0.0011, d_{i}=94$.
Thus the number of lambs infected $\left(L_{i n}\right)$ in season $n$, was calculated from the total number of lambs and the probability of a lamb being bitten by an infected tick whilst the lamb was susceptible, such that

$L_{i n}=L\left[\left(B_{i}+C_{i}\right) / T\right] \cdot\left(D_{n} / d\right)$.

The number of nymphs infected in season $n+1$ is then calculated from multiplying together (a) the number of larvae per lamb in season $n$, (b) the number of infected lambs, (c) the probability of a lamb then becoming viraemic and (d) the probability of a larvae developing and successfully feeding on a host as a nymph (calculated from data on the ratio of each tick stage observed on hosts), thus

$B_{i n+1}=L_{i n}(v+f a-1) B / d$,

where $f$ is the number of days ticks feed.

Similarly, the number of adult ticks infected in season $n+1$ is calculated from the number of infected nymphs in season $n$ multiplied by the probability of feeding as an adult, added to the product of the number of susceptible nymphs in season $n$, the number of infected lambs, the probability lambs become viraemic and the probability of nymphs feedings as an adult tick. Thus

$$
\begin{aligned}
C_{i n+1}= & B_{i n}(C / B) \\
& +\left(B_{n}-B_{i n}\right) L_{i n}[(v+f b-1) / d](C / B) .
\end{aligned}
$$

This model was not constructed to incorporate tick dynamics. Thus, with a fixed tick population size, the model is not realistic at high and low lamb densities as these influence dramatically the tick biting rate per day through dilution or concentration, although it does function well around the densities of lambs required for viral persistence.

\section{RESULTS}

\section{Maternally-derived louping-ill virus antibody titres in lambs}

On 3 of the 4 intensively studied farms all (S2, E1), or virtually all (S1), lambs appeared to have some maternally acquired antibodies to louping-ill virus when first sampled at approximately 4 weeks of age (Table 1). However, on farm E2, where yearlings were vaccinated but the relative level of LIV was low (see Table 2), $26.5 \%$ of lambs appeared to be susceptible to the virus. Correspondingly, the reciprocal titres (log transformed) of this antibody were significantly different among the 4 intensively studied farms in 1995 (ANOVA, $F_{3,126}=18 \cdot 6$, $P<0.001$ ), with titres lowest on farm E2 (Fig. 2, Table 1). Farm E2 also had a greater variance in titres than the other farms (Table 1). Farm E1, which did not vaccinate, had lower levels of antibody than the Scottish farms, despite similar infection rates. As lambs grew, maternally-acquired antibody declined and thus lambs became susceptible to 
Table 1. The percentage of lambs of different ages susceptible to louping-ill virus infection on the four intensively studied farms.

(Farms S1, S2, and E2 conducted yearling vaccinations against LIV.)

\begin{tabular}{lcccc}
\hline \hline Farm... & S1 & S2 & E1 & E2 \\
\hline Age (weeks) & & & & \\
4 & $3 \cdot 7$ & 0 & 0 & $26 \cdot 5$ \\
12 & $14 \cdot 8$ & 3 & $2 \cdot 7$ & $38 \cdot 2$ \\
22 & $77 \cdot 8$ & $30 \cdot 3$ & $75 \cdot 7$ & $82 \cdot 4$ \\
Mean (s.E.) & $2 \cdot 6(0 \cdot 1)$ & $3 \cdot 0(0 \cdot 08)$ & $2 \cdot 4(0 \cdot 08)$ & $1 \cdot 8(0 \cdot 19)$ \\
titre at 4 & & & & \\
weeks & & & & \\
\hline \hline
\end{tabular}

infection with LIV (Table 1), although on the farms with high initial titres, there were still few susceptible lambs by mid-summer. However, by the end of September, over three quarters of lambs were susceptible on 3 of the farms.

\section{Seroconversion of lambs to louping-ill virus}

Between 11.5 and $80 \%$ (mean (s.E.) $=0.47(0 \cdot 07))$ of lambs in the 9 extensively sampled flocks exhibited antibodies to louping-ill virus by the autumn. As expected, there was a significant positive relationship between the number of adult female ticks on lambs in mid-July and the seroprevalence of lambs in that flock at the end of the season $\left(r^{2}=0 \cdot 85, F_{1,4}=23 \cdot 33\right.$, $P<0 \cdot 01)$.

Results from the intensively sampled flocks showed that some lambs seroconverted in early summer before clipping in mid-July, although very few lambs seroconverted on farm E2 (Table 2). During the latter part of the summer seroconversion rates were higher and by the time lambs were 18-22 weeks old, some lambs had seroconverted on all farms.

By the end of March the next year, when yearling lambs were vaccinated against louping-ill virus, $66.7 \%(n=24)$ of yearlings on farm S1 still had detectable levels of louping-ill antibodies, including the 3 individuals which had seroconverted before they were 3 months old. Titres had, however, declined on average by $2 \cdot 0$ dilutions since October. These lambs thus appeared to have been sensitized at the time of infection and have actively acquired immunity.

\section{Virus amplification through viraemia}

Despite a large number of lambs seroconverting to louping-ill virus, it was calculated that only a small percentage $(0 \cdot 01-5 \%)$ were likely to have been viraemic on infection (Table 2). Even when the most extreme assumption was made, that all lambs that had no detectable antibody when they went missing died of louping-ill, no more than $15 \%$ of lambs on the farm with the highest lamb losses could have been viraemic on louping-ill virus infection.

\section{The effect of increasing force of infection on the number of lambs viraemic: Model $A$}

The non-linear relationship between infection rates and lamb viraemia was explored using a simple model of the transmission dynamics (Fig. 1). The model suggested that the percentage of lambs viraemic on any day varied with the force of infection (Fig. 3) but the general pattern was similar, even for low forces of infection, if the model was run beyond the realistic length of the grazing season depicted in Fig. 3. Under this general pattern, the percentage of lambs that were viraemic each day rose to a peak, as the rate of lambs becoming susceptible after losing maternal immunity increased. The percentage of lambs that were viraemic then declined, once all lambs had become susceptible or the rate of lambs becoming susceptible was less than the rate that they were infected. Flocks subject to a low rate of infection reached this peak at 120 days, when all lambs had become susceptible. At a very high force of infection, many immune lambs were infected without ever becoming susceptible and thus these could never become viraemic. Thus the percentage of lambs viraemic initially tracked the rate of lambs becoming susceptible, with numbers peaking 75 days after turnout but then declined rapidly as the rate of lambs becoming susceptible decreased below the constant

Table 2. Lamb tick burdens, lamb seroconversion/infection rates and percentage of lambs that become viraemic on infection with louping-ill virus on 4 intensively studied farms

\begin{tabular}{|c|c|c|c|c|c|c|c|}
\hline \multirow[b]{3}{*}{ Farm } & \multirow{3}{*}{$\begin{array}{l}\text { No. days } \\
\text { lambs on } \\
\text { hill ground }\end{array}$} & \multirow{2}{*}{\multicolumn{2}{|c|}{$\begin{array}{l}\text { Mean (s.E.) number adult } \\
\text { female ticks per lamb }\end{array}$}} & \multirow{2}{*}{\multicolumn{2}{|c|}{$\begin{array}{l}\text { No. lambs seroconverted/ } \\
\text { infected per day } \times 10^{-3}\end{array}$}} & \multicolumn{2}{|c|}{$\begin{array}{l}\text { Estimation of percentage lambs } \\
\text { potentially viraemic when infected }\end{array}$} \\
\hline & & & & & & \multirow{2}{*}{$\begin{array}{l}\text { Assuming } 10 \% \text { of } \\
\text { viraemic lambs died } \\
\text { of LI }\end{array}$} & \multirow{2}{*}{$\begin{array}{l}\text { Assuming all } \\
\text { missing lambs } \\
\text { died of LI }\end{array}$} \\
\hline & & July/Aug. & Sept./Oct. & summer & summer & & \\
\hline S1 & 103 & $1 \cdot 3(0 \cdot 3)$ & $1 \cdot 2(0 \cdot 3)$ & $5 \cdot 09$ & $11 \cdot 4$ & $3 \cdot 4$ & $7 \cdot 1$ \\
\hline $\mathrm{S} 2$ & 106 & $0 \cdot 04(0 \cdot 04)$ & $0 \cdot 4(0 \cdot 2)$ & $0 \cdot 78$ & $8 \cdot 88$ & $1 \cdot 1$ & $7 \cdot 6$ \\
\hline $\mathrm{E} 1$ & 127 & $24 \cdot 0(1 \cdot 6)$ & & $5 \cdot 48$ & $11 \cdot 4$ & $0 \cdot 03$ & $15 \cdot 0$ \\
\hline $\mathrm{E} 2$ & 98 & $0 \cdot 2(0 \cdot 03)$ & & 0 & $1 \cdot 06$ & $0 \cdot 01$ & $10 \cdot 9$ \\
\hline
\end{tabular}




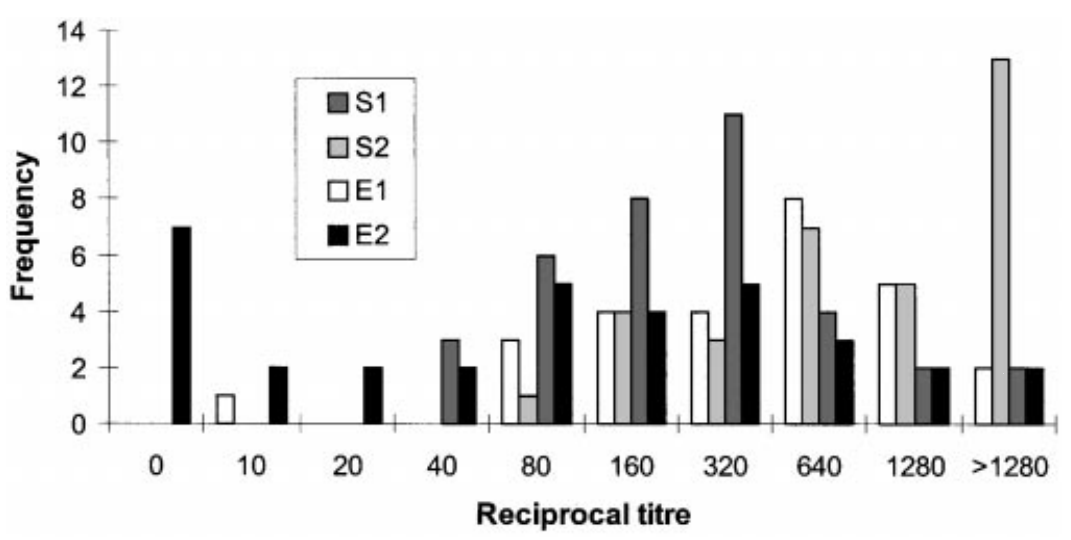

Fig. 2. Frequency distribution of lamb antibody titres on the 4 intensively studied farms.

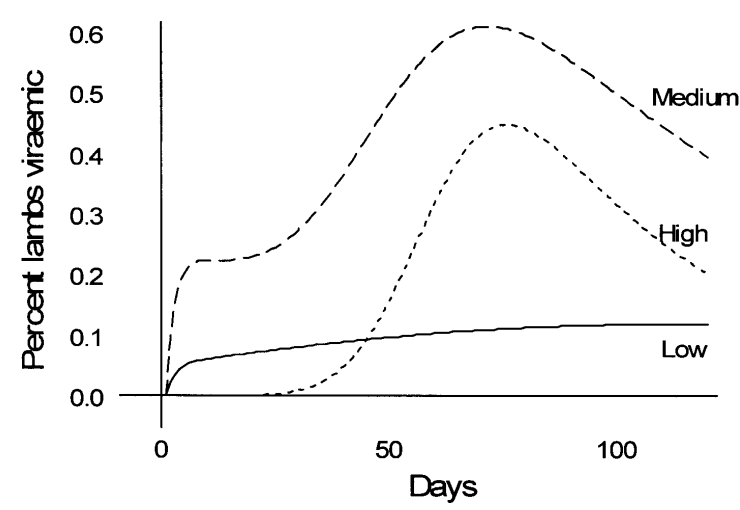

Fig. 3. The percentage of lambs that are viraemic each day under high, medium and low forces of louping-ill infection. Parameter values for high, medium and low rates of infections respectively are $0 \cdot 0227,0 \cdot 0119$ and $0 \cdot 0011$ for $b ; 1,0.9$ and 0.75 for $p ; 2 \cdot 406,2 \cdot 204$ and 1.75 for $A_{\text {int }}$ and $0 \cdot 3,0 \cdot 4043$ and $1 \cdot 13$ for $\sigma^{2}$. In all cases $A_{\text {crit }}$ is taken to be $1, g=0.5$ and $\gamma=0.0215$ (based on a half-life of 14 days).

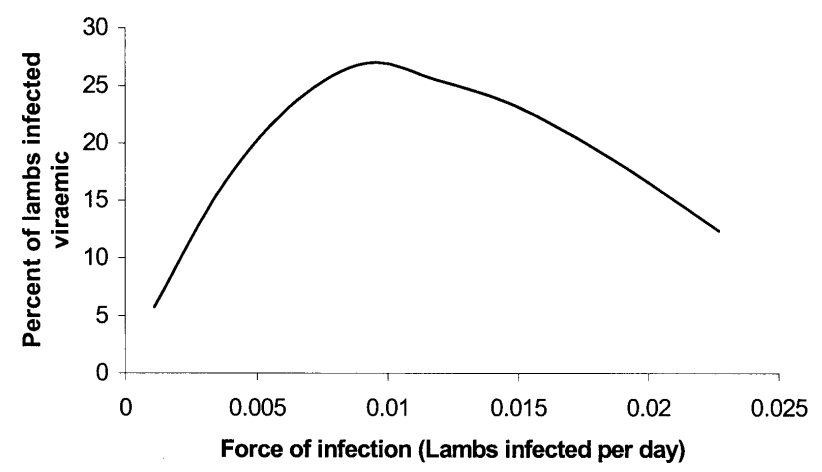

Fig. 4. Variation in the total percentage of lambs in a flock that become viraemic after infection with varying rates of louping-ill virus infection, $b$.

force of infection. The total percentage of lambs that became viraemic each season varied with the force of infection (Fig. 4). Initially, increasing infection rates increased the percentage of viraemic lambs as more lambs were infected in total but, at very high rates of infection, a lower percentage of the flock amplified LIV than at intermediate rates. At these high forces of infection, a high proportion of lambs are likely to

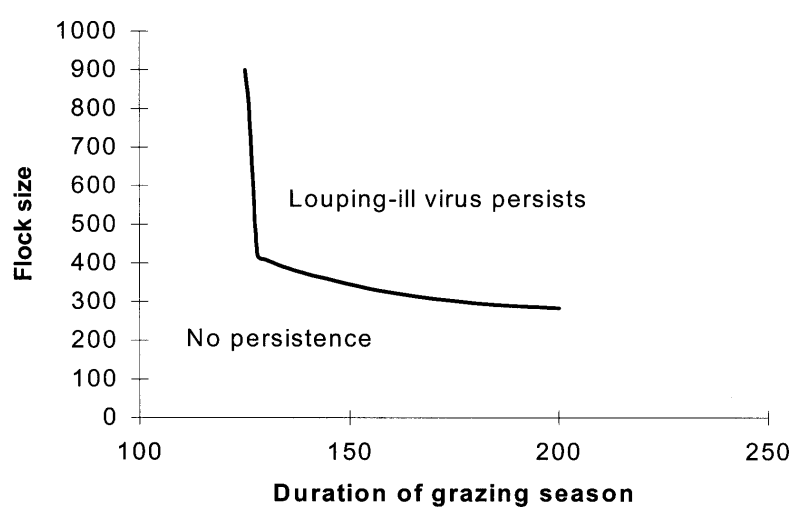

Fig. 5. Conditions of flock size and grazing season duration required for louping-ill virus persistence.

be infected whilst still protected by maternally acquired immunity and thus proceed directly to the permanently immune class without ever becoming susceptible. If this rate of infection is high enough, endemic stability may be achieved.

Conditions for louping-ill virus persistence: Model B

Under the assumptions of the model, louping-ill virus could persist in vaccinated flocks through the infection of lambs, if the flock size and the length of the grazing season were great enough (Fig. 5). Where the grazing season was 140 days long, at least 371 lambs were required. When the length of grazing season was less than 140 days, the number of lambs viraemic each day became unstable and cycles were generated. Nevertheless the virus could persist if the grazing season was reduced by another 10 days, if flock size was increased. Irrespective of flock size the virus could not persist if the grazing period were less than 130 days.

\section{IS CUSSION}

This study has shown that some lambs from both naturally infected flocks and vaccinated flocks can be susceptible to louping-ill virus infection at birth or turnout. When ewes are vaccinated only once and 
reinfection rates are low, antibody levels in ewes decline to relatively low levels 1 year post-vaccination (Reid \& Pow, 1995) and a considerable proportion of lambs apparently receive no or very little colostral antibody. However, on farms that vaccinated against louping-ill virus and where ewes were frequently re-infected, initial colostral antibody levels were high and few lambs became susceptible until later in September. Thus on farms where ewes are singly vaccinated, but where there is a high prevalence of louping-ill, lamb losses to louping-ill might be rare, particularly in the early summer. Nevertheless, this study adds weight to the recommendation that breeding ewes should be vaccinated twice against LIV to achieve high antibody titres and thus protect lambs as fully as possible in all circumstances (Reid \& Pow, 1995).

\section{Amplification of louping-ill virus by lambs}

Amplification of louping-ill virus, which requires ticks to acquire virus from the blood of a host, depends on the host exhibiting a viraemia of more than $10^{4}$ plaque-forming units per $0 \cdot 2 \mathrm{ml}$ of blood. Despite high exposure rates to LIV on 3 of the farms in this study, viraemia in lambs appears rare in these field situations; under the most extreme assumptions, not more than $15 \%$ of lambs in these flocks could have been viraemic and thus amplified the LIV. Two factors might explain this result. First, lambs had generally high levels of maternallyderived antibody in flocks where the force of infection is high, as ewes were superinfected. Thus lambs were likely to be infected whilst they still have some maternal immunity : in experiments such lambs did not become viraemic (Reid \& Boyce, 1976). Second, and in the contrasting situation where the force of infection is very low, although lambs had lower levels of maternal antibody and were susceptible for more of the tick activity season, the probability of lambs being infected is low. However, further exploration of the balance between infection rates and rates of lambs becoming susceptible suggested that at very high levels of infection, fewer lambs could have amplified louping-ill than at more moderately high levels. In this situation, few losses may be seen in lambs or older sheep, even if no vaccination is carried out and 'endemic stability' may arise. In this situation there is a climax relationship between host, agent vector and environment where all coexist such that minimum morbidity and mortality are present in the host (Norval, Perry \& Young, 1992).

The situation of endemic stability has some weak empirical support from the observation that $75 \%$ of yearlings on farm S1 already had protective levels of antibody at the time of vaccination. Thus, if these yearlings were not vaccinated few losses may have occurred and such losses may not be noticed or diagnosed in an extensive production system. Furthermore, a low level of lamb losses may be tolerable in many systems, with the cost of vaccination outweighing that of losses. The stability of this situation in a sheep-only system may, however, be fragile and cycles of viral prevalence could result. If few sheep are viraemic, the prevalence of virus will drop, reducing the force of infection and thus also reducing superinfections and the chance of lambs being infected whilst still protected by maternal immunity. Thus, in time, more animals may be susceptible, and more losses may result, leading again to an increase in infection rates. This scenario may explain the pattern of mortality observed on louping-ill infected farms where large losses are seen only intermittently. If, however, the force of infection is somehow otherwise maintained, endemic stability for sheep may occur (Deem et al. 1996).

\section{Do lambs explain LIV persistence?}

Although there were theoretical conditions under which louping-ill virus could persist through LIV infection of lambs, it is unlikely that this is a general explanation for LIV persistence in areas where sheep flocks are vaccinated. First, the length of grazing season (or tick activity period) was a critical parameter determining persistence in our model and was geater than that observed in almost all the study flocks. Indeed, the importance of this parameter indicates that restricting the time that lambs are left on the hill in the late summer/autumn is one way in which a shepherd can prevent lamb losses due to louping-ill. Second, infection leading to viraemia is not the sole condition for louping-ill amplification; ticks must also acquire infections by feeding on these lambs. When lambs are treated with acaracide, although ticks may attach and infect their host, few ticks will feed successfully or become infected and thus the chance of LIV transmission to a new host is low. Nevertheless, in some management situations the period of susceptibility at the end of the year coincides with both a time of poor tick control and with an autumn tick rise and these conditions may allow LIV persistence. Thus the results of this study illustrate the importance of good tick control and how it can reduce not just the chance of infection, but also viral amplification and persistence.

\section{Conclusion}

Despite the long-term use of louping-ill vaccine on some farms, LIV appeared to persist on all the study sites, as at least some lambs seroconverted to LIV in each of the extensively sampled flocks by the end of the summer. However, amplification of LIV by lambs does not account for LIV persistence either in the flocks in this study, or more generally in most upland management systems in the British Isles. 
Thus alternative explanations to account for loupingill virus persistence must be sought. Recent experimental studies point to the importance of nonviraemic transmission in mountain hares (Lepus timidus) and thus their potential role as amplifying hosts (Jones et al. 1997). In addition, if non-viraemic transmission in immune sheep occurs, as with Lyme disease (Ogden et al. 1997), it could also account for viral persistence. Further work is currently underway to investigate this possibility.

We would like to thank the farmers who allowed their sheep to be sampled and who often helped to restrain sheep for sampling. Kevin Begg and Davie Taylor, were always willing to perfect their sheep handling skills as, on occasion, were Simon Thirgood, David Howarth and David Ogilvie. Sarah Cleaveland, Daniel Haydon and Simon Thirgood kindly commented on the manuscript. This work was supported by a grant from the NERC, the Game Conservancy Scottish Research Trust and the SOAFED.

\section{REFERENCES}

BEASLEy, s. J., CAMPBell, J. A. \& Reid, H. W. (1978). Threshold problems in infection of Ixodes ricinus with the virus of louping-ill. In Tick-Borne Diseases and their Vectors (ed. Wild, J. K. H.), pp. 497-500. Edinburgh University Press, Edinburgh.

Clarke, D. H. \& CASAls, J. (1958). Techniques for haemagglutination and haemagglutination-inhibition with arthropod-borne viruses. American Fournal of Tropical Medicine and Hygiene 7, 561-573.

DEEM, S. L., NORVAL, R. A. I., YONOW, T., PETER, T. F., Mahan, S. M. \& BURRIDGE, M. J. (1996). The epidemiology of heartwater: establishment and maintenance of endemic stability. Parasitology Today 12, 402-405.

GORDEN, W. S. (1934). The control of certain diseases of sheep. Veterinary Record 14, 1-8.

GRAY, J. s. (1991). The development and seasonal activity of the tick Ixodes ricinus: a vector of Lyme borreliosis. Review of Medical and Veterinary Entomology 79, 323-333.

Hudson, P. J. (1992). Grouse in Space and Time. The Game Conservancy Trust

HUDSON, P. J., NORMAN, R., LAURENSON, M. K., NEWBORN, D., GAUNT, M., JONES, L., REID, H. W., GOULD, E., BOWERS, R. \& DOBSON, A. (1995). Persistence and transmission of tick-borne viruses: Ixodes ricinus and louping-ill virus in red grouse populations.

Parasitology 111, S49-S58.

Jones, L. D., DAvies, C. R., Steele, G. M. \& Nuttall, P. A.

(1987). A novel mode of arborvirus transmission

involving a nonviraemic host. Science 237, 775-777.

JONES, L., GAUNT, M., HaIls, R., LAURENSON, K., HUDSON, P. J., REID, H. W. \& GOULD, E. (1997). Amplification of louping-ill virus infection during co-feeding of ticks on mountain hares (Lepus timidus). Medical and Veterinary Entomology 11, 172-176.

MiLne, A. (1947). The ecology of the sheep tick, Ixodes ricinus $\mathrm{L}$. The infestations of hill sheep. Parasitology 38, 34-50.

NORVAL, R. A. I., PERRY, B. D. \& YOUNG, A. S. (1992). The Epidemiology of Theileriosis in Africa. Academic Press, London.

OGDEN, N. H., NUTTALl, P. A. \& RANDOlPh, S. E. (1997). Natural Lyme disease cycles maintained via sheep by cofeeding ticks. Parasitology 115, 591-599.

Papoulis, A. (1965). Probability, Random Variables and Stochastic Processes. McGraw-Hill, New York.

REID, H. W. (1975). Experimental infection of the red grouse with louping-ill virus (Flavivirus group). I. The viraemia and antibody response. Fournal of Comparative Pathology 85, 231-235.

REID, H. W. (1978). The epidemiology of louping-ill. In Tick-Borne Diseases and their Vectors (ed. Wild, J. K. H.), pp. 501-507. Edinburgh University Press, Edinburgh.

REID, H. W. \& BOYCE, J. B. (1976). The effect of colostrum-derived antibody on louping-ill virus infection in lambs. Fournal of Hygiene 77, 349-354.

REID, H. W., BUXTON, D., POW, I., BRODie, T. A., HOLMES, P. H. \& URQUHART, G. M. (1986). Response of sheep to experimental concurrent infection with tick-borne fever (Cytoecetes phagocytophilia) and louping-ill virus. Research in Veterinary Science 41, 56-62.

REID, H. W., DUNCAN, J. S., PHILliPS, J. D. P., Moss, R. \& Watson, A. (1978). Studies on louping-ill virus (Flavivirus group) in wild red grouse (Lagopus lagopus scoticus). Fournal of Hygiene 8, 321-329.

REID, H. W. \& POW, I. (1995). Antibody response of sheep following administration of louping-ill virus vaccine. Veterinary Record 136, 638-639.

Woolhouse, M. E. J., HAYdon, D. T., PEARSON, A. \& KITCHING, R. P. (1996). Failure of vaccination to prevent outbreaks of foot and mouth disease. Epidemiology and Infection 116, 363-371. 